\title{
O Sistema Único de Saúde e o projeto civilizatório: cenários, alternativas e propostas
}

Rosana Teresa Onocko-Campos 1

Oswaldo Yoshimi Tanaka 2

doi: 10.1590/0102-311X00116621

Os congressistas do 4o Congresso Brasileiro de Política, Planejamento e Gestão em Saúde, reunidos de 22 a 26 de março de 2021 em plataforma virtual, saudaram o futuro avistado nas conferências, grandes debates, mesas-redondas e comunicações orais como expressão do direito de todos à saúde e à vida. O Sistema Único de Saúde (SUS), definitivamente, precisa ser defendido como nosso orgulho, portador de esperança.

$\mathrm{Na}$ abertura, Jurema Werneck estimulou o ativismo social e político com sua conferência Desigualdades e Pandemia: Que Democracia é Necessária para um Projeto Efetivamente Includente?. Essa provocação marcou o tom de um congresso que se nos apresentou vivo, aguerrido e caloroso, contrariando a temida suspeita de frieza pelo seu formato virtual. Foi difícil tomar a decisão de realizar um congresso inteiramente virtual, o primeiro nessa modalidade desenvolvido pela Associação Brasileira de Saúde Coletiva (Abrasco).

$\mathrm{O}$ desenho desse congresso foi intensamente participativo 1,2. Durante quase dois anos, um grupo de 80 pesquisadores da área de Política, Planejamento e Gestão em Saúde (PP\&G) de todo o país constituiu a Comissão Científica do Congresso, que se agrupou em dez eixos temáticos para organizar o encontro.

A organização dos eixos foi direcionada para aprofundar a análise crítica que possibilitasse o reconhecimento de novas estratégias e novas abordagens em planejamento e gestão para a defesa do direito à saúde da população brasileira ${ }^{3}$.

Cabe realçar que a comissão científica assumiu propositalmente a ideia de que a espinha dorsal desse congresso seriam as comunicações coordenadas, síncronas e assíncronas, nas quais os distintos atores sociais da área apresentaram suas produções. Essa dinâmica facilitou o processo de diálogo com novos pesquisadores que estão adentrando o campo e gerando uma nova massa crítica no setor saúde.

Dentre os eixos temáticos, o de Planejamento, Gestão e Avaliação em Saúde recebeu proporcionalmente o maior número de trabalhos (197) e os de Relações Federativas e Regionalização da Saúde e Política Científica, Tecnológica e de Inovação o menor número, com 36 resumos cada. No meio, ficaram outros eixos importantes como Politica, Gestão e Atenção Hospitalar (57) e Sistemas e Redes de Atenção (48), só para exemplificar como a produção da área é vasta, mas se distribui desigualmente, o que - talvez - merece um estudo mais detalhado
1 Faculdade de Ciências Médicas, Universidade Estadual de Campinas, Campinas, Brasil. 2 Faculdade de Saúde Pública, Universidade de São Paulo, São Paulo, Brasil. 
das relações entre estímulo à produção científica, formação de novos grupos de pesquisa e demandas prementes do SUS e da sociedade brasileira.

$\mathrm{Na}$ apresentação e nos debates dos 326 trabalhos aprovados para apresentação oral e nos 736 trabalhos das comunicações assíncronas, diversificadas abordagens metodológicas possibilitaram o debate epistemológico sobre a emergência sanitária, as ameaças de novas pandemias e a instituição de modos de vida igualitários e emancipatórios.

Nas comunicações síncronas, a organização temática, que permitiu interação entre relatos de experiência e de pesquisa, fez a diferença ao colocar o mundo da prática e da vida em contato com as melhores produções e inovações da área de PP\&G.

As 16 mesas-redondas tiveram também uma peculiaridade: foram desenhadas de forma descentralizadas pelos investigadores de cada eixo - e posteriormente validadas pela comissão científica como um todo. Elas buscaram intencionalmente em seu desenho importantes atualizações das principais questões temáticas da área. No debate, trouxeram contribuições que polemizavam entre si e marcaram a entrada de novos atores na cena científica.

A variedade de temas foi grande como pode se constatar: (1) Estado, políticas sociais e de saúde; (2) Política, gestão e redes de atenção no Brasil; (3) Trabalho e Educação em saúde: cenários e alternativas; (4) Democracia e participação social; (5) Vacina e vacinação como política: desafios em tempo de pandemia; (6) Protagonismo das ciências sociais e humanas em saúde na compreensão e enfrentamento de epidemias e da pandemia da COVID-19; (7) Crise institucional e judicialização das relações federativas no Brasil: impasses e perspectivas; (8) Construindo uma agenda para o campo "Política, gestão e atenção hospitalar no SUS”; (9) Economia política do financiamento da saúde no Brasil: alternativas ao neofascismo e ultraneoliberalismo; (10) Prospecções no enfrentamento da COVID-19 no Brasil; (11) Cenário internacional e resposta dos países no enfrentamento da pandemia de COVID-19; (12) Reflexões sobre privatização, SUS e o mercado da saúde; (13) Abordagens e dispositivos de intervenção na gestão e produção do cuidado; (14) Planejamento, avaliação e gestão na conjuntura atual: o que temos na bagagem e o que precisamos inventar; (15) Pesquisa, desenvolvimento e inovação e saúde; e (16) Frente pela vida: o Brasil precisa do SUS 4.

Houve grande diversidade de participantes nas mesas: pesquisadores sêniores e jovens pesquisadores; e pessoas negras, indígenas e de comunidades e movimentos sociais, que enriqueceram a área com seus lugares de fala singulares e suas leituras de mundo.

O pensador italiano Franco Berardi ofereceu uma conferência sobre O Enigma do Beijo: O Distanciamento Pandêmico na Evolução Psíquica do Gênero Humano, em que provocou os participantes a refletir sobre as redes de afetividade no contemporâneo e as marcas subjetivas que serão deixadas pela longa pandemia.

A pandemia e a situação dramática do Brasil no contexto internacional foram o pano de fundo e atravessaram todas as mesas e grandes debates. O congresso foi realizado enquanto a humanidade (e o Brasil em particular) sofre os efeitos das tentativas de acabar com o que resta do estado de bem-estar social e se depara com a premente necessidade de defender perspectivas efetivamente democráticas.

Os dois grandes debates colocaram aos congressistas perguntas disparadoras. No primeiro, Sonia Fleury e Renato Lessa refletiram sobre a questão "Há futuro para a democracia no Brasil?”; e no segundo, Joice Berth, Christian Dunker e Cida Bento discorreram sobre a provocação: “É possível sonhar uma sociabilidade sem infâmia no Brasil pós- pandemia?”.

A área de PP\&G faz - e sempre fez parte - do tripé disciplinar que sustenta a Saúde Coletiva. O 4o Congresso Brasileiro de Política, Planejamento e Gestão em Saúde pôde apre- 
sentar à população brasileira que estamos de pé, para defender o direito à saúde conquistado na Constituição de 1988.

No congresso, foi possível pensar alternativas para a saúde da população no contexto da pior crise sanitária, ambiental, política e econômica da história brasileira. Houve propostas de enfrentamento ao descaso e à desorganização do poder público, em um contexto de imenso sofrimento, luto e dor que a população brasileira está vivendo.

Pensando a PP\&G como área de pesquisa e de produção de conhecimento, o congresso mostrou que temos construído um campo indutor de práticas e serviços, que se desenvolve entrelaçando a produção científica em um processo reflexivo sobre os entraves, os desafios atuais e as soluções factíveis para o fortalecimento do sistema de saúde brasileiro. A produção de conhecimento em PP\&G é primordialmente aplicada e engajada em defesa da saúde como direito.

Houve a instituição do Prêmio Hesio Cordeiro para destacar, dentre as 326 comunicações coordenadas, 30 menções honrosas nos eixos: Desafios do SUS (11 menções); Alternativas de implementação (9 menções); e Propostas de mudança de estratégias para o futuro próximo (10 menções).

O congresso permitiu reconectar saúde com democracia, saúde com desenvolvimento sustentável, saúde com políticas para diminuir a exclusão, a discriminação e o preconceito. Durante o evento, foi possível defender estratégias direcionadas a assegurar o direito universal à saúde e a superação das relações sociais predatórias.

Os trabalhos apresentados e os temas debatidos nas mesas-redondas e nas oficinas précongresso identificaram estratégias políticas e recursos técnicos com potencialidade para interferir na organização das agendas governamentais e dos movimentos sociais (as atividades do congresso estão disponíveis em https://www.youtube.com/watch?v=e2astT6xSq Q\&list=PLWGsEtFnOh_KU_eZq5LArSHF8z99V_gPv).

Essas iniciativas estimularam formas inovadoras de decisão, mobilização e articulação intersetorial, visando construir unidade política para interromper a exclusão em curso e possibilitar a formulação de projetos societários populares e democráticos.

O congresso conseguiu se constituir em um marco histórico de resistência e formulação inovadora de propostas de intervenção nos distintos níveis de ação política e técnico-operacional para o fortalecimento do SUS.

A saúde coletiva brasileira, herdeira da saúde pública de Oswaldo Cruz, promotora do capítulo da saúde da constituinte que estabeleceu que no Brasil "saúde é direito de todose dever do Estado”, compareceu ao 4o Congresso Brasileiro de Política, Planejamento e Gestão em Saúde para dizer que está de pé e pronta para reconstruir 5 . Na cerimônia de fechamento do congresso foi aprovada a Carta de Esperança no Futuro, pois, como disse o poeta Vinicius de Moraes - em estrofe que fecha a Carta: "a tristeza tem sempre uma esperança de um dia não ser mais triste não". 


\section{Colaboradores}

Os autores participaram igualmente da redação do texto.

\section{Informações adicionais}

ORCID: Rosana Teresa Onocko-Campos (00000003-0469-5447); Oswaldo Yoshimi Tanaka (00000002-5653-0794).
1. Giatti LL. O carater adaptativo da pesquisa participativa: rompendo com a monocultura de saberes. In: Toledo RF, Rosa TEC, Keinert TM, Corizo CT, organizadores. Pesquisa participativa em saude: vertentes e veredas. São Paulo: Instituto de Saúde; 2018. p. 39-49.

2. Furtado JP, Onocko-Campos RT, Moreira MIB, Trapé TL. A elaboração participativa de indicadores para a avaliação em saúde mental. Cad Saúde Pública 2013; 29:102-10.

3. Gilson L, Orgill M, Shroff ZC, editors. A health policy analysis reader: the politics of policy change in low- and middle-income countries. Geneva: World Health Organization; 2018.

4. Machado CV, Lima LD, Bousquat A, PereiraSilva MV, Fernandes DRA, Artmann E, et al. Produção de conhecimento em política, planejamento e gestão na revista Ciência \& Saúde Coletiva. Ciênc Saúde Colet 2020; 25:4681-91.

5. Victora CG, Barreto ML, do Carmo Leal M, Monteiro CA, Schmidt MI, Paim JS, et al. Health conditions and health-policy innovations in Brazil: the way forward. Lancet 2011; 377:2042-53. 